\title{
CERVANTES ANTI-NOVELISTA
}

Al tratar de escribir una historia de la novela en la España moderna, he tenido que plantearme un angustioso problema previo. ¿Cómo se explica que la patria de don Quijote se muestre tan esquiva a la fabulación, que los escritores buenos o malos rehusen el novelar, a la antigua o a la moderna, precisamente en los tiempos en que el género conquista públicos y crítica; cómo es posible que las ficciones de más éxito en Europa lleguen tan tarde a nosotros? A todas estas cuestiones se ha respondido siempre con la palabra "decadencia", se ha dado por supuesto que una debilitación del genio creador de España menguaba su posible participación en los logros de la novela moderna. Si entre nosotros, en el siglo xviII, en los comienzos del xix, se hubiesen escrito malas novelas, el eclipse del genio español hubiera bastado a explicar el fenómeno. Pero salvo excepciones que se cuentan con los dedos, y sobran muchos dedos, no se escriben novelas ni buenas ni malas, y en cambio se traducen muchas. Podría aducirse la existencia de la censura, pero la censura no fué nunca tan infranqueable que impidiese la circulación por España de fábulas extranjeras; no hubiera podido impedir completamente la floración de una novela española que hubiera satisfecho los gustos generales.

Sin que decadencia, desgana, y la opresión gubernativa dejen de explicar aspectos parciales del fenómeno, es claro que no bastan a explicarlo por entero. Esas mismas rémoras requerirían a su vez explicación. Yo creo encontrarla en la valoración, o mejor, desvaloración de la novela que entonces se hace, desvaloración que inhibe a los más altos espíritus, que intimida a los otros. Cierto, una gran demanda o una efervescencia creadora atenida a las exigencias del público, hubieran podido determinar una producción copiosa, con o sin el espaldarazo de la alta crítica. Así ocurrió en Francia e Inglaterra. El enrarecimiento de la atmósfera española, evidente, contribuyó poderosamente a la inhibición de los escritores españoles, o por lo menos a emperezarlos. Porque éstos podían defenderse con argumentos derivados de teorías estéticas que aquí tratamos de explicar. La novela desvalorada no merecía atención, y España había producido ya la única buena -doblemente valiosa por lo que de antinovela tenía.

Parodiando el título de un famoso discurso de don Agustín Durán, podría escribirse otro sobre la influencia de la crítica en la decadencia 
de la novela española. Espero poder adicionar las sucintas notas que aquí ofrezco con las aportaciones de cuantos por este problema se interesen.

Aquella estupenda majadería de Montesquieu, reveladora del más lamentable aspecto de la crítica del siglo xvifl francés - la crítica por el desconocimiento1-: "Le seul de leurs livres [des Espagnols] qui soit bon est celui qui a fait voir le ridicule de tous les autres" (Lettres persanes, LXXVIII), sería incomprensible si no la interpretáramos en el tiempo y en el ambiente en que fué escrita. Estas palabras eran el último cumplimiento de una tendencia prefigurada en la crítica del siglo anterior. ¿Qué hacer de la novela, este género sin precedentes en la Antigüedad, del que nada supo Aristóteles y del que nada dijo Horacio? Desde que el neoclasicismo intenta la hazaña imposible de injertar sus pretensiones racionalistas en el tronco del arte antiguo, respetando en éste aquello que menos valor podía tener a los ojos de la razón, los géneros literarios y las categorías estéticas en que se fundan, la novela, por su carencia de precedentes, quedó en muy mala postura. Apenas se salvará la pastoril, asociada tradicionalmente a otros géneros nobles. Boileau, en su Dialogue des héros du roman (1665), se burlará despiadadamente de las novelas a la moda -aunque en el prólogo haya una mención aparte, elogiosa, de L'Astrée. En el Arte poética, posterior en nueve años (1674), parece aceptar el género sin entusiasmo, pero en términos expresos; o mejor aún, reconoce su existencia, pero es claro que diputa las novelas como un frívolo divertimiento cortesano, casi como una advertencia de lo que el arte serio no debe ser. Aunque por razones dialécticas pueda decir ocasionalmente otras cosas. Cuando en su carta a Perrault, tomando el partido de los modernos, defiende las novelas, hablará de ellas como de poemas en prosa, probablemente con la intención discriminatoria que hemos de ver en seguida ${ }^{2}$. Porque de un modo general, su enemiga contra la novela, contra les romans, es sensible. Al contrario de Lope de Vega, para quien novelas y comedias venían a ser una misma cosa, y su fin "dar gusto al pueblo, aunque se ahorque el arte":;, Boileau apenas habla de la novela sino para mostrar lo que no debe

\footnotetext{
1 Para la apreciación del conocimiento o desconocimiento que Montesquieu tuvo de España, remitimos ahora al artículo de P. Barrik̀re, "Montesquieu et l’Espagne", BHi, XLIX, 1947 , págs. 299 y sigs.

" "Je montrerais qu'il y a dés genres de poésie où non seulement les Latins ne nous ont point surpassés, mais qu'ils n'ont même pas connus: comme par exemple, ces poc̀mes en prose que nous appelons romans" (Oeurres pó́tiques, Paris, Flammarion, s. a., pág. $\left.35^{2}\right)$.

${ }^{3}$ El desdichado por la homa, en $B A A E E$, vol. XXXVIII, pág. 1. $b$.
} 
ser el teatro. (Estos pasajes de Boileau condenaban el nuestro con mayor dureza, aunque implícitamente, que el ataque declarado contra "el coplero de allende el Pirineo"). Al burlarse de la novela en el primer opúsculo, al aludirla en el otro, Boileau indica con bastante claridad lo que por novela entendía: un relato de galanterías refinadas, incapaz de acoger las grandes pasiones de la tragedia; la novela que hicieron Mlle de Scudéry o La Calprenède, y en ello estaba de acuerdo con autores que segura o probablemente no le eran simpáticos: Scarron, que había opuesto la nouvelle española al roman francés, con ventaja de la primera ${ }^{\sharp}$ o Furetière, que considerará también la novela como poema en prosa, pero lo hará en burlas, y rebutirá su libro de pasajes irónicos y paródicos contra los romans, que para él, como para Scarron, eran cosa distinta de los libros que consideraba recomendables y deseables". En Scarron, la fórmula cervantina se opone claramente al roman, pero se refiere sobre todo a las Novelas ejemplares al establecer esta oposición. La boga del Quijote impondrá a la crítica otros rumbos. Todas estas cosas se le escapan a Boileau, genial en esto de no ver más allá de sus narices. Lo que aquí nos importa es notar que desde entonces, y sobre todo por la autoridad de Boileau, la novela está ausente de la teoría del arte, cuándo condenada, cuándo tolerada a duras penas. Va adquiriendo sus derechos por la conquista de los públicos, y se mantiene en el favor de las cortes como un advenedizo afortunado.

En todas estas críticas pudieron entrar muy bien ideas cervantinas, si no enteramente originales, reelaboradas por el autor español, que hubieron de lograr el vuelo prodigioso que les permitía la gran difusión del Quijote. Allí se oyen, en boca del Canónigo especialmente, mil lindezas sobre el desorden y el disparatar frenético de los libros de caballerías, pero también cuerdas razones sobre la posibilidad de poner orden en ese caos, frenar la fabulación tumultuosa y salvar la ficción en prosa para el arte. El Canónigo, con una ingenuidad que parece dar la razón a Lope de Vega, no deja de decir: "cuando los leo [los libros de caballerías], en tanto que no pongo la imaginación en pensar que son todos mentira y liviandad, me dan algún contento; pero cuando caigo en la cuenta de lo que son, doy con el mejor dellos en la pared..." (I, Xlix). Pero supuesto que el contento existe, espontáneo e irreprimible, y es una especulación razonada, alterada por las "mentiras" y disparates que reconoce, lo que lo refrena, ¿por qué

4 “. . les Français seuls en savaient faire de bons [romans] et les Espagnols avaient le secret de faire de petites histoires qu'ils appellent nouvelles qui sont bien plus à notre usage et plus selon la portée de l'humanité ... Si l'on faisait des nouvelles en français aussi bien faites que quelques unes de celles de Michel de Cervantès, elles auraient cours autant que les romans hérö̈ques" (Le roman comique, ed. Magne, Paris, Garnier, s. a., pág. 130).

"Le roman bourgeois, Paris, Garnier, s. a., pág. 5 . 
no moderar las mentiras y suprimir los disparates, es decir, por qué no reducir las novelas a las reglas del poema épico? Poema en prosa, más libre que el de los antiguos, fecundísimo por esa misma libertad, posibilitado de apoyarse en las categorías estéticas más dispares. "Porque la escritura desatada destos libros da lugar a que el autor pueda mostrarse épico, lírico, trágico, cómico, con todas aquellas partes que encierran en sí las dulcísimas y agradables ciencias de la poesía y de la oratoria; que la épica tan bien puede escribirse en prosa como en verso" (I, xLVII). Porque los autores de libros de caballerías no han tenido en cuenta todas estas espléndidas posibilidades, por no haberse atenido a "arte ni reglas", han perdido la ocasión de "hacerse famosos en prosa, como lo son en verso los dos príncipes de la poesía griega y latina" (I, XlviII). Este colofón que el Cura pone a los razonamientos del Canónigo resumen una concepción de la novela, mantenida por preceptistas e historiadores hasta hace relativamente poco tiempo: la novela es épica en prosa. Es curioso encontrarla expresada en el libro que arrancaba definitivamente a la novela de su matriz épica.

Estas ideas van a constituir la línea de defensa de la novela en el siglo xvII, y cuando más torpe y formularia es la expresión que se les da, tanto es más sensible el equívoco en que se incurre. Si Francisco de Quintana -o Francisco de las Cuevas, como prefiere ser llamadoexplica la división de un libro suyo diciendo: "divídole en poemas porque poema es nombre genérico que no sólo a los versos comprehende, sino a la prosa, como insinúa Cicerón...; demás de que, si se consulta la lengua griega ...., poema es lo mismo que invención, que ni desdice destos sucesos, ni del modo de referirlos" "; expresando cosas certísimas y falsísimas a la vez, no tenía en cuenta sobre todo que entre estos "poemas" suyos y lo que desde antiguo venía llamándose así no resultaba paridad alguna. Si Furetière dice también: "un roman n'est rien qu'un poème en prose" sus burlas mismas se deduce que los romans nada tienen de poemáticos - ni aun de poéticos.

Tal vez porque los siglos xvir y xvir fueron tan pobres de inspiración épica mereció tanta atención el poema heroi-cómico, boga que ha de favorecer grandemente el reconocimiento "de derecho" de la gran obra de Cervantes. Cuando Fielding justifique, en el prefacio de Joseph Andrews, la suya propia, lo hará con palabras que convienen igualmente al Quijote, y que quizá de la contemplación del Quijote deriven, libro tan leído, estudiado e imitado por el novelista inglés. Pero las generalidades de antes se matizan ahora con adjetivos carac-

- Experiencias de amor y fortuna, Madrid, 1723, prólogo. (La primera edición es de 1626 ).

¿ Le roman bourgeois, loc. cit. 
terísticos. "A comic romance is a comic poem in prose", dice Fielding, que cita constantemente a Cervantes, pareándolo con los mayores

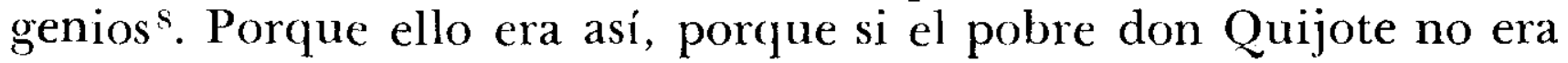
quinto o sexto nieto de rey el libro de su vida sí podía considerarse como quinto o sexto nieto de la Batracomiomaquia, la historia quedaba salvada, puesta en línea con las grandes obras de clara genealogía.

En ese mismo prólogo a Joseph Andrews, hará Fielding otra distinción que merece tomarse en cuenta. Intentando otra "salvación", la de Télémaque, dirá de éste: "appears to me of the epic kind, as well as the Odyssey of Homer", añadiendo que no debe ser confundido con relatos de otra especie, "such as are the voluminous works commonly called romances, namely Clelia, Cleopatra, Astraea, Cassandra, the Gran Cyrus and innumerable others, which contain, as I apprehend, very little instruction or entertainment". Y en efecto, desde que se concibió la idea de asimilar la novela a la épica, el problema no quedaba resuelto con un simple trastrueque de rúbricas o etiquetas. Si la novela era un poema, la novela había de ser poemática. El ejemplo de Fénelon determina una serie de dignificaciones del relato novelesco, jalonadas a lo largo del siglo xvin y los principios del xix, puesto que Chateaubriand puede considerarse incluído en esta corriente. Todo aquello (los libros de Marmontel, de Florian, de Barthélemy, de Lantier y de otros) se leyó bastante en España, aun pasada la época romántica. Aquella tendencia hasta produjo una imitación, si no española, peninsular, de lectura muy frecuente entre nosotros aun en época muy próxima: $O$ feliz independente do mundo $e$ da fortuna (1779) del P. Teodoro de Almeida, de que hay una traducción castellana de 1785 , que ignoro si será la primera, y una imitación del P. Andrés Merino, que salió anónima en 1786: Poema. La mujer feliz, dependiente del mundo y la fortuna, Madrid, Imprenta Real, 3 vols. en $8^{\circ}$. En el prólogo de su libro, Almeida declara haber tomado por modelo al "gran Arzobispo de Cambrai en su famoso Telémaco y otras obras de este género, en las que con la suavidad del néctar encantador de la poesía, se dan las máximas más saludables para las costumbres"'. Ya veremos en seguida la importancia que tiene el aspecto moral; por ahora retengamos sólo cuanto al arte se refiere, las consecuencias prácticas que el autor deriva de su primer propósito, por qué se decidió por la prosa, después de intentar escribir su libro primeramente en verso rimado y luego en verso suelto, y cómo elige sus personajes "para que no se dijera que degeneraba en novela lo que era poema" ${ }^{10}$. Las palabras subrayadas indican tan

\footnotetext{
"Joseph Andrews, Author's preface.

"Edición de Madrid, 1842, págs. 9-10.

10 Ibid., pág. 17.
} 
claramente cuanto pudiéramos desear una tentativa de dignificación del género, tras ciertas separaciones y deslindes, que implícitamente dan a entender lo que de la novela, sin más, pensaban las gentes letradas y piadosas de aquellos tiempos. Por suerte o por desgracia, el P. Almeida no era hombre de llevar a cabo tal empresa de rehabilitación.

Leyendo estas cosas, tan al alcance de todos en general, y en que ya no se para mientes por parecernos un poco pueriles, se tiene la impresión de que los que las escribieron propendían a enlazar con la literatura noble lo que tenían por bueno, y a rechazar lo malo al confuso infierno de la novela. Las dignificaciones se hacían siempre a posteriori, cuando un libro famoso, vencidos los primeros embates de la crítica, se afirmaba en la estima de los doctos. Por razones puramente estéticas, es muy difícil convenir en lo que todos los autores citados nos dicen. Había mucha más "épica" en el Amadís que en el Quijote. En realidad, lo que venían a decir es que en el Amadis había épica seria, mala, y en el Quijote excelente épica cómica. Y luego, aun el Amadis se había perdido de vista - no obstante las recomendaciones de Cervantes mismo. La novela era ya esto que hacían Mlle de Scudéry o La Calprenède - recuérdense las citas de Fielding. A todo ello se oponía Cervantes.

Y luego había el problema moral. Boileau había escrito en su citada carta a Perrault: "nous avons chez nous des modèles [des romans] qu'on ne saurait trop estimer, à la moral près, qui y est fort vicieuse et qui en rend la lecture dangereuse aux jeunes personnes"11. Misteriosamente nos parece que la vieja inquina de moralistas y teólogos, tan adversos siempre a la lección de "mentiras" por un vulgo ávido de ficciones, que se distraía en ellas del importante negocio de su salvación, renace en las exigencias de los neoclásicos. Cuando el menguado, pero honradísimo, Sempere Guarinos escribe sobre el Feliz de Almeida o de su imitación por el P. Merino, dice cosas que parecen retrotraernos ciento cincuenta años arreo: "Ambas obras son muy útiles para la instrucción de la juventud, y si se comparan con el Amadis, la Celestina, la Eufrosina, las novelas de Zayas y de Lope..., que formaban la biblioteca de los petimetres o galanes de aquellos tiempos, se verá la poca justicia con que se prefieren en muchas cosas al nuestro" "12. ¿Qué no le parecería Cervantes, contado por

${ }^{11}$ Oeuvres, ed. cit., pág. 352; cf. Fielding, loc. cit.

12 Ensayo de una biblioteca española de los mejores escritores del reinado de Carlos III, vol. IV, Madrid, 1787, pág. 66. - Es curioso recordar que el Feliz de Almeida fuese una de las lecturas juveniles de Pereda, que habla sin duda de una experiencia propia cuando refiere "la hazaña... que yo rematé siendo niño, leyéndome... Misseno o El hombre feliz, la obra más de bien que se ha escrito en el mundo, pero cuya lectura han terminado muy pocos cristianos y no ha repetido ninguno, yo inclusive" (La Puchera, Obras completas, vol. XI, pág. 
los críticos contemporáneos como el debelador de aquella mala literatura, al menos de lo que más ridículo parecía ahora a los lectores razonables? (Nadie se acordaba ya del perdón concedido por Cervantes al Amadis, ni de que, aunque con atenuaciones, había declarado a la Celestina libro casi divino.)

La pobreza increíble de la novela española en el siglo xviII se puede explicar en parte por esta nueva desvaloración de la novela, de los libros llenos de mentiras, lección de gentes de pocas luces. No veo mención de novelas entre las lecturas de los ingenios de mayor valor de aquella centuria; o si raramente se las encuentra, los libros en cuestión, aunque a la ficción pertenezcan, no son considerados como novelas. Si Meléndez, por ejemplo, celebra a Marmontel, es por las ideas y el estilo, no por las fábulas. Escribiendo a Jovellanos dirá: "El que también me gusta mucho es Marmontel en su Belisario; los primeros capítulos son, a mi ver, capaces de hacer olvidar las mayores desgracias; lo he leído todo bastantes veces, pero cada vez con más gusto, y me sucede lo que a Saint-Évremont con nuestro Don Quijote...” Y otra vez: “. . . acabo de leer una obra de Marmontel cuyo título es Los Incas . . . especie de novela y poema épico . . , cosa como suya, de un estilo tan delicado como el de los cuentos, y llena de máximas y sentimientos de humanidad, pero que exagera con exceso nuestras crueldades y apoya fuertemente la tolerancia. Yo esta clase de libros la leo con el mayor gusto, porque nada me embelesa tanto como las máximas de buena moral, y éstas mejor esparcidas y como sembradas en una obra llena de imaginación y de primores"'13. Como se ve, lo que interesaba no era lo novela, o quier poema, sino la filosofía. Ellos, los solitarios de Salamanca, de Sevilla o de Madrid, prefieren formularla en verso. Los galeotes de la pluma que ya prefiguran a los otros forzados famélicos que conocieron Mesonero o Larra, si paran mientes en la novela, prefieren traducir obrezuelas venidas de fuera, recogidas al azar. El siglo xviII, que al margen de la preceptiva y con las intenciones más diversas produce en todas partes tanta novela, no tiene en esa empresa la colaboración de la patria de Cervantes, que sólo sabe entonces reivindicar para sí el Gil Blas, con la acritud del que se ve desposeído de algo muy suyo.

329). El carácter autobiográfico del personaje que habla se confirma por otra alusión que ocurre en Pedro Sánchez, Ob. comp., XIII, pág. 9, y de ambas se deduce que por aquellos años de 1848 , poco más o menos, el libro de Almeida no tenía ya cabida sino en los hogares piadosos, donde sólo importaba que el libro fuera "muy de bien".

${ }^{13} B A A E E$, vol. LXIII, págs. 76 y 85 . 
Sería exagerado decir, como se ha dicho, que las traducciones de novelas cayeron sobre España como un alud; pero como en efecto se traducía mucho de todo, y como la producción indígena era tan pobre - en realidad inexistente- y la otra destacaba por contraste, el exceso de traducciones provocó censuras en que implícitamente se incluían las obras novelescas. Un nuevo argumento de los críticos aparece ahora, siempre el mismo: tanta traducción bastardea y corrompe la lengua. En realidad, lo que expresaban esos reproches, análogos a otros proferidos por los críticos del siglo siguiente, es el malestar de una conciencia intranquila por el hecho de la decadencia, disgustada del lugar secundario que España ocupa en Europa y de su servidumbre espiritual con respecto a los otros países, a Francia sobre todo. Tanta bulla de traducciones, aunque fuesen malas, que no todas lo fueron, resultaba en definitiva beneficiosa, y la lengua, lejos de ser bastardeada, resultó enriquecida, o capaz de serlo, una vez cultivada por manos más capaces. El ramplón, pero sincero Sempere Guarinos, pudo escribir sobre el caso palabras más justas que las de otros críticos de más brillante minerva: "La mayor parte de los traductores de lenguas vulgares han afeado nuestro idioma con voces y frases nuevas y con cierta languidez muy agena al carácter y genio de los españoles. Mas por otra parte la han enriquecido de ideas, y aun en cuanto al estilo, han contribuído a purgar éste de ciertos vicios que se habían hecho generales en nuestros libros, y ahora no lo son ya tanto, cual es el de la hinchazón, sutileza, cadencia, hipérboles y metáforas de que antes estaban empedradas las obras, aun de los más sabios escritores. Algunos pensarán de diverso modo..."14 De plumas necias nunca sale buen lenguaje, cualquiera que sea la disciplina del estilo. Los discursos del pedante contrahecho, en La derrota de Moratín, no pecan ciertamente de galicistas; son más bien infraculteranos.

Pero atengámonos a lo que a novelas se refiere. Un Forner o un Iriarte están demasiado imbuídos en las ideas de su siglo para fijarse en las novelitas que empiezan a circular por los estrados, y al hablar de malas traducciones nunca descienden a detalles. Nunca se sabe a ciencia cierta de qué hablan cuando generalizan de esta suerte: "... traductores de libritos franceses que han corrompido el habla de nuestra patria y puéstola en el extremo que lloran los buenos". Si el censor es alguna vez más explícito, recalcará sobre los falsos adornos con que abruman el lenguaje "los predicadores y novelistas de este nuestro siglo", pero la protesta lo confunde todo: "lecciones de física y química, anécdotas, historietas de los monarcas del norte, novelas, moralidades, devocionarios ..." Es curioso que Forner, que sólo dice esto de la novela mala, no sea más explícito sobre la buena,

14 Biblioteca, vol. VI, Madrid, 1789, pág. 230. 
o que él tuviera por tal; quizá pensaba que no existía semejante novela. No obstante el culto que rinde a Cervantes, Forner ignora la novela, y cuando en las Exequias describe el cortejo fúnebre, apenas se refiere de pasada a "los novelistas, capitaneados por el insigne Cervantes" 15, sin más explicaciones. La defensa de la lengua llega a ser un lugar común de escaso valor crítico; en todo caso no creo que nadie pretenda atribuir a las traducciones de novelas culpas especialmente graves en el proceso de corrupción que todos lamentan. Lo formulario de esas quejas y su verdadero carácter se echan de ver, por ejemplo, contrastando la epístola de Iriarte a Cadalso, en que aquél se lamenta del modo como se deja perder la lengua castellana, con su sátira macarrónica contra el mal gusto en las escuelas, en la que las quejas de los pedantes siguen los mismos términos en que a cada paso prorrumpen los casticistas, y con las de éstos podrían confundirse:

\section{O Hispani, Hispani, quae vos locura moderna Quae furibunda mania novos studiare libretes Incaprichavit? Sic vestras Francia testas Offuscat miserabiliter, soplatque dineros!16}

La novela, como tal novela, no cuenta para los críticos más avisados del clasicismo. Las novelas son fruslerías de un interés pasajero, o libros sospechosos en su moralidad y que requieren extrema vigilancia. En ello coinciden censores talentosos y adocenados. "A pesar de todos los elogios que se han dado a los romances y libros de caballerías, confesamos de buena fe que esta lectura divierte a un número muy corto de gentes, es perjudicial a muchos e inútil para todos", se lee en El Correo de los Ciegos. "Un célebre filósofo prueba en sus discursos políticos que la lectura de las novelas causa tan malas consecuencias en los ánimos juveniles como la de Machiavelo en los de los viejos" ${ }^{1 \tau}$. El filósofo podría ser Montesquieu, podría ser Voltaire. ¿No había dicho éste, refiriéndose a las novelas de Mme de Villedieu, pero rechazando todas en general, que eran "des productions des esprits faibles qui écrivent avec facilité des choses indignes d'être lues par les esprits solides"? ${ }^{18}$ La novela es un esca-

${ }^{15}$ Forner, Exequias de la lengua castellana, ed. Clás. cast., Madrid, 1925, págs. $98,115,263,257$.

1" BAAEE, vol. I.XIII, pág. 44; cf. ibid., págs. 24-25.

17 Núm. 60, 19 de mayo de 1787 (I, pág. 253). Aunque se refiere concretamente a las caballerías combatidas en el Quijote, todo lo posterior caía bajo la misma condenación.

${ }_{18}$ Le siècle de Louis XIV, Oeuvres, Paris, Dupont, $182 \%$, vol. XIX, pág. 208. Contradicción parece la carta a los editores de la Bibliothéque Universelle des Romans, pero es aparente; allí se trata de Petronio, de Apuleyo y de autores así; sobre lo contemporáneo no hay nada. Un curioso pasaje de la comedia Le droit du seigneur (1762), II, III, indica que Voltaire adopta ante lo novelesco 
moteo de la verdad, cosa indigna de la filosofía ${ }^{19}$. Como entre nosotros, de todos modos, escaseaban, y la española no existía ya o no existía aún, pudo prescindirse de ella en absoluto. Un detalle revelador: en 1806, La Minerva publicaba una adaptación de Jeannol et Colin de Voltaire, sin nombre de autor, por supuesto, bajo el título de Rafael y Carlitos; pues bien, una frase del original, que en español, dadas las circunstancias, no hubiera tenido sentido alguno, "Faites des romans, c'est une excellente ressource à Paris", se ha convertido en "Métete a traductor, que es oficio socorrido" 20. Las dos frases no pueden ser más expresivas de lo que era la canalla literaria madrileña y del valor que al roman de sus días daba Voltaire, indicio de cómo hay que considerar los que él mismo escribió.

La repulsa de la novela por la crítica española del siglo xvir es tanto más curiosa por ocurrir en un país que se envanece, y entonces como nunca, de ser la cuna de don Quijote; en tiempos en que los prestigios de Cervantes cobraban aumentos insospechados. Pero es que Cervantes, aunque capitanee a los novelistas en las Exequias de Forner, parecía otra cosa y más que un novelista ${ }^{21}$. Y además fué ... un anti-novelista. Exagerando enormemente Forner su desprecio por las especulaciones filosóficas y contraponiéndoles algo que él llama filosofía práctica, llega a hacer del Quijote una sublime exposición de esta filosofía, con lo que resulta que las verdaderas ficciones, para él, son los más célebres sistemas filosóficos. "Para mí - dice Forner- entre el Quijote de Cervantes y el Mundo de Descartes o el Optimismo de Leibnitz no hay más diferencia que la de reconocer, en la novela del español, infinitamente mayor mérito que en las fábulas filosóficas del francés y del alemán; porque siendo todas las ficciones diversas sólo en la materia, la cual no constituye

una actitud irónica análoga a la que apreciamos en Furetière (Oentres, ed. cit., vol. VIII, pág. 28).

19 Por ser tan raras las menciones de novelas cn este tiempo, citaré este pasaje a propósito de una descripción de la Alhambra: "No es un edificio como los que se ven en todas partes, sino un palacio muy superior a todos los que hallamos en las novelas" (Espiritu de los diarios, 1788, pág. 821). La novela, en estas alusiones triviales, sigue no siendo concebible sino como irrealidad pura.

${ }^{20}$ Llamó la atención sobre este curioso escrito J. SARrallh, "Notes sur une traduction espagnole de Jeannot el Colin de Voltaire trouvce dans la revuc de Madrid La Minerva du 26 mars 1806", RLComp, II, 1922, págs. 611-612. La adaptación, plagio o como se llame, lleva la iniciales C. P.

${ }^{21}$ Recućrdese aquí lo que ya había dicho Cadalso: que en el Quijote "el sentido literal es uno y el verdadero otro muy diferente", y que debajo de su apariencia de obra extravagante, era "un conjunto de materias profundas e importantes" (Cartas marruecas, ed. Clás. cast., Madrid, 1950, pág. 147). Y no se olvide, por otra parte, que implícitamente, en la Introducción a sus cartas, Cadalso retrotrae a Cervantes aquella "novela satírica de costumbres" de que más tarde hablará Mesonero. 
el mérito de las fábulas, en el Quijote logró el mundo el desengaño de muchas preocupaciones que mantenía con perjuicio suyo; pero las fábulas filosóficas han sido siempre el escándalo de la razón" "22. Las disputas de los filósofos llenan el mundo de preocupaciones y de engaños, mientras que el Quijote es una luz divina en la tiniebla humana. Y suponiendo a Cervantes nada menos que discípulo de Luis Vives, le cree instigado por la doctrina del maestro a la empresa de desterrar el "inepto gusto" de los libros de caballería... franceses. No sé si en las palabras de Forner habrá una protesta velada y una fina ironía contra la necia sentencia de Montesquieu; el pasaje es tan curioso que es menester citarlo: "Habíanos venido de Francia el inepto gusto a los libros de caballería... Clama Vives contra el abuso; escúchale Cervantes, intenta la destrucción de tal peste, publica el Quijote y ahuyenta, como a las tinieblas la luz al despuntar el sol, aquella insípida e insensata caterva de caballeros despedazadores de gigantes y conquistadores de reinos nunca oídos" ${ }^{23}$.

Cervantes había desterrado las malas novelas - no había otras; las otras eran "poemas", aunque Forner no sienta empacho en llamar novela al Quijote, en lo que pocos de su siglo le acompañan. ¿Cabía mayor título de gloria para el autor español? "Gracias al autor de Don Quixote (exclama un autor extrangero)... tenemos menos que temer los fatales efectos que hasta entonces imprimieron algunas lecturas en los ánimos de nuestros conciudadanos ... , cuya ponzoña se introducía imperceptiblemente ya en sus entendimientos, ya en sus corazones. ¿Y será posible creer (continúa el mismo filósofo) que hay todavía un gran número de alucinados que no quieren perdonar a Miguel de Cervantes el haber destruído las caballerías antiguas, pretextando que con esto se ha debilitado ... el amor .... a las virtudes?" "24 Los que sólo se interesan por la ficción tratarán de salvarla a la manera como la salvaba Fielding, y Torres Villarroel dirá: "en el linaje de la epopeya ridícula no se encuentra invención que pueda igualarse al donaire de esta historia, ni se puede inventar contra las necedades caballerescas invectiva más agria". Cervantes aparece así primero como el anti-novelista por excelencia, tanto más

".: Oración apologética por la España y' su mérito literario, Madrid, Pueyo s. a., pág. $2 y$.

:3 Oración apologética..., pág. $15^{6}$

* El Comveo de Madrid, núm. 6o, 19 de mayo de 1787 (I, pág. 253). Este texto es tanto más curioso cuanto que parece adelantarse a aquella otra tontería tan incomprensible como la de Montesquieu, la romántica:

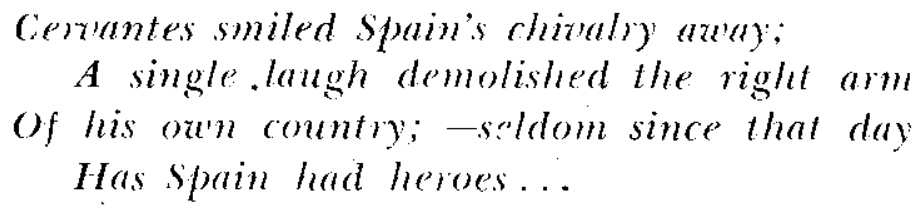

(BYRON, Don Juan, XIII, XI). 
meritorio cuanto que no sólo pone fin a la máquina confusa de las caballerías disparatadas, sino que regulariza cuanto en el arte de la ficción merece ser salvado. Lampillas hará de él un rival triunfante del Ariosto: “¿No es una novela el inmortal Quijote? ¿Y dejó por eso de observar el gran Cervantes todas las reglas que hacen deleitable e instructiva la fábula? Guardó la unidad de la acción, mezcló como debía los episodios con la acción principal, ideó aventuras extraordinarias, bien que verosímiles, pintó naturales los caracteres de los personajes y les hizo hablar en el estilo que les convenía". Mayor modernidad resulta del juicio de Marchena, que, clásico y todo, era hombre de otro temple y se atenía a los resultados más que a las teorías: "Fstaba por decir que es preciso ser tan loco como el héroe de Cervantes para figurarse que puede ser un insensato el protagonista de una epopeya: mas considerado como héroe de novela, nunca otro más interesante que Don Quijote se ha presentado en la escena"'.5. Cuanto más cerca está un autor de esta época de la pura ortodoxia clasicista, tanto más propenso lo veremos a interpretar torcidamente la novela de Cervantes. Así Jovellanos: "La acción del Quijote reúne en sí circunstancias tan precisas, tan oportunas, tan convenientes a la nueva especie de poemas con que él enriqueció la literatura, que no es fácil, ni acaso posible hallar otra tan acomodada". Pero "Cervantes supuso a don Quijote como existente en la misma época en que escribió su acción, y éste ... ciertamente es un gravísimo defecto de su poema, y que le hizo caer a Cervantes en otros muchos ..."26 He aquí un caso ejemplar de cómo ese concepto de lo "poemático" puede oscurecer la comprensión del libro de Cervantes hasta hacerlo contradictorio consigo mismo.

Como la novela seguía siendo todo aquello que no podía acogerse a una noble tradición, la novela era tan inadmisible como los libros de caballerías expulsados por Cervantes. Si bajo la pluma de críticos literarios el juicio que los libros de ficción merecen se matiza siempre de inquietudes morales, ¿qué no dirán los moralistas de oficio, custodios profesionales de las costumbres públicas? ¿Qué no hará un Gobierno paternal y vigilante? En 27 de mayo de 1799, una providencia del Consejo de Castilla vedaba el imprimir novelas, y aunque la medida no se aplicase nunca a raja tabla, no es dudoso que muchas denegaciones de licencias se inspiraban en el celo por la moral. A veces estas censuras se apartan del caso concreto a que debe. rían atenerse y generalizan ampliamente. Así leemos en un docu-

$2:$ Estos pasajes y otros varios que podrian anadirse y que no vale la pena detallar aquí, pueden verse en la Bibliografia critica de Rrus, III.

"Juicio critico de un nuevo "Quijote", en Obras escogidas, ed. Ángel del Río, Clá.; cast., Madrid, 19.6, vol. III, pág. 313. 
mento que las novelas, "lejos de contribuir a la educación e instrucción de la nación, sólo sirven para hacerla superficial y estragar el gusto de la juventud, aficionándola a aventuras amorosas y lances caballerescos, sin ganar nada las costumbres, y por consiguiente no se debe permitir la impresión ni publicación de semejantes obras inútiles". "I a pintura viva de una pasión hace mucha impresión en los jóvenes, cuyas cabezas se llenan de estas ideas romancescas y se valen después de ellas para seducir a la inocencia; con el pretexto de enseñar virtudes, se enseñan vicios, y basta para prueba el fruto que han producido tantas novelas como hemos visto traducidas, cuyo menor defecto es estropear nuestra lengua castellana". "Todas las obras de esta especie" están llenas "de enamoramientos y galanterías", "lo que puede perjudicar a las buenas costumbres de la gente joven, particularmente de las señoritas, que suelen ser los únicos libros que traen entre manos" $2 \tau$. Este papel está fechado en 1808 ; en él la "niña romántica" se anuncia. Y es la niña romántica la que va a ganar la partida, como la ganaron en otras ocasiones y en otras partes otras niñas noveleras contra la opinión de los críticos más ilustres. Pero por de pronto, ganará la batalla por el favor que presta a traducciones y adaptaciones que le permiten soñar acaecimientos imposibles en su ambiente. Las gentes de letras siguen otros derroteros.

Con maravillosa clarividencia, haciéndose cargo de todos los aspectos del problema, un crítico que escribía pocos años antes del advenimiento del romanticismo, expuso lo que a su juicio constituía la humildad y servidumbre de la novela. En 1822, la revista de Madrid El Censor publicaba un artículo sobre la Matilde de Mme Cottin traducida por García Suelto, y en ese importantísimo ensayo leemos, con asombro creciente:

De todos los géneros de literatura, el novelesco es el más infeliz, porque jamás se ha podido elevar a la dignidad de clásico. La novela de Heliodoro entre los griegos, y la de Apuleyo entre los latinos están en cuarta o quinta línea, a pesar de que $E l$ asno de oro pertenece al género satírico. El Quijote y el Telémaco no deben su celebridad al género que aparentan tener, sino al que encubren. Éste es estimado por sus principios políticos, aquél por la abundancia de verdadero cómico que rebosa en todos sus capítulos. Fs esto tan cierto, que si el primer libro de nuestra literatura no contuviese más que episodios novelescos como los de Fernando y Cardenio, apenas sería leído ... [Sigue hablando de Rousseau, Richardson, Fielding (que pone a par de Pigault-Lebrun y A. La Fontaine). Todos estos libros]

27 Gonzálaz Panfexca, Estudio histórico sobre la censura gubernativa ..., Madrid, 1934-1949, vol. II, núms. 538, 549 Y $55^{1}$ (págs. 296, 316 y 317). 
o se leen por otra cosa, o no han conseguido más que entretener algunos momentos la imaginación... Mas no han elevado el género sobre la clase de las frivolidades agradables. No es extraño, pues, que le hayan abandonado al bello sexo, y desde la autora [sic] de La Casandra, de narcótica memoria, hasta la justamente célebre madama de Stael, ha sido la ocupación favorita de las plumas femeninas...

El desdén con que es mirada la novela entre los literatos, hace que este género no esté sometido a más reglas que las generales del estilo y la verosimilitud; reglas que los escritores novelistas no tienen dificultad en violar, o por parecer originales, o para producir efectos extraordinarios y maravillosos.

Hay muchas causas para que no se haya dado importancia al género novelesco en la literatura. La primera de todas es su facilidad. Todo escritor que posea el arte del estilo y que esté dotado de una fantasía brillante y de un alma dócil a la impresión de los afectos, puede escribir una novela con tanta facilidad como una carta. Hay la misma diferencia de este género a cualquiera otro prosayco como del drama sentimental a la verdadera comedia.

Además, la novela es frívola esencialmente. Pasiones amorosas, sucesos estraordinarios, episodios increíbles; en una palabra, entretenimiento y recreo es lo que ofrece a sus lectores. Para dar mezclada con todo este aparato la instrucción que recomienda Horacio en su utile dulci es necesario mucho ingenio, y el hombre de mucho ingenio abandona las formas novelescas y busca otras más verosímiles, más estimadas para clásicas, para propinar la dosis de instrucción que quiere difundir. Exceptúase, sin embargo, la novela satírica, aunque según lo que hemos dicho, más bien debía llamarse sátira que novela. Este nombre conviene solamente a aquellas en que la acción y los sentimientos ocupan esclusivamente al lector. No tendremos dificultad en confesar que es un género muy poco importante en literatura; pero lo es en moral, y mucho más que la Poesía, la historia y los demás géneros filosóficos. La novela es y será irremediablemente, por más severa que sea la educación doméstica, el único libro en que un sexo entero y gran parte del otro aprenderá en la época tempestuosa de la juventud la operación más importante para el hombre, cual es la de dirigir sus afecciones. No son tan interesantes para este objeto la epopeya, la lírica, la historia ni el drama como esos libros novelescos que tanto desprecian los literatos.

Hay un hecho cierto e irremediable. La juventud lee y leerá novelas con preferencia a cualquier otro libro, porque es lo que más debe divertirla e interesarla ... Desprecie, pues, el literato cuanto quiera un género que no puede aspirar a la cumbre del Parnaso; el moralista y el político cometerán un gravísimo yerro en despreciarle, pues es un medio constante y poderoso de in- 
fluir sobre la juventud. En vano se prohibirá que los jóvenes lean novelas; los jóvenes las leerán...28

Es del mayor interés ver corroborado en este texto coetáneo el desprecio de los profesionales de las letras hacia este afortunado advenedizo. Y desde entonces es comprobable que cuantos escritores nuestros, contemporáneos del fervor romántico, habían tenido una formación clásica, rechazaron con acrimonia la novela como un género espurio, como una recreación insustancial y frívola, y que, contra la novela moderna, hubieran mantenido la censura si de ellos dependiera el hacerlo. Aun cuando hayan de contradecirse con su posterior conducta literaria. Leídas esas páginas, comprendemos que Mesonero, que tanto mal escribió de las novelas en boga, aspirara a la "novela satírica de costumbres" - como se ha visto, la única permitida-, y que, fracasado en su intento, se orientara hacia lo que podríamos llamar "el costumbrismo puro". Y ése es el caso de Mora, traductor de Walter Scott y gran denigrador, aunque no lo diga expresamente, de la novela ${ }^{29}$, y el de Alcalá Galiano, que tan agudo fué, y que, tal vez el primero, entrevió las posibilidades del costumbrismo novelesco ${ }^{30}$, lo que no obsta para que pase con la mayor esquivez ante el triunfo de la novela moderna, o que merme la importancia de la que inmediatamente la precede. Ello es comprobable, aunque en un solo caso ejemplar, en nuestros días mismos. Basta que un autor, aunque haya cultivado la novela, aunque deba a este cultivo sus mejores éxitos, se haya formado en el espíritu del siglo xviri, para que se conduzca como heredero del menosprecio que por el género sintió aquella centuria. ¿Cómo podremos juzgar la obra de Valera dentro del marco literario de su tiempo cuando le oímos hablar con tan poca estima de esos "libros de entretenimiento" que eran las novelas? E1 crítico, que todavía en 1900, en

2s El Censor, núm. 85, 16 de marzo de 1822 (XV, págs. 24-26).

29 No pueden referirse a otra cosa las ásperas frases que a ciertos engendros contemporáneos dedica en el prólogo a los Ensayos de Lista, Sevilla, 1844.

${ }^{30}$ En un excelente artículo publicado en el Athenaeum de Londres dice Galiano, después de referirse a las novelas históricas que empiezan a producirse en España: "Nor is the production of the common novel to be discouraged in spite of the trash which is sure to spring from the cultivation of this branch of fiction. It would be well to direct the attention of the Spaniards to their own country and the realities of its everyday life, which might, moreover, be followed by another beneficial consequence -that of rendering Spanish life, as it is, more fully known to foreigners... It is the fault of the Spaniards themselves that they are not better known..."; "retaining some national customs, but having adopted much that is foreign, their very peculiarities being widely different from those of former ages, and for the most part referable to the storms which it has been the lot of the existing generation to toil through and to lie under" ( 1894 , pág. 453c). Hasta en su postulación de este costumbrismo novelesco es Galiano más discreto que otros autores nuestros. 
un discurso académico, hacía aquellos distingos entre el novelista sin aspiraciones, "poeta modestísimo, llano y vulgar, cuyo principal propósito es divertir o interesar agradablemente a sus contemporáneos", y el poeta épico o lírico "que tiene o ha de tener aspiraciones más elevadas", parece hombre de otros días, un discípulo de Lista o de Quintana, íntimamente persuadido de que la gloria está al fin del sendero recorrido por Tasso o por Milton, y para quien ninguno

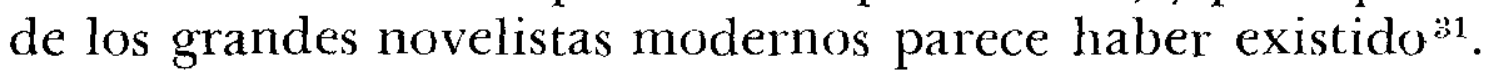

El planteamiento de este pequeño problema, que -ya se ha visto - no es ajeno a otras literaturas, es para la española central cuestión. Me parece ver en esta actitud, que tanto sobrevive al romanticismo, la más poderosa razón del tardío advenimiento de nuestra novela, de la ramplonería de la crítica española ocupada en justificarla o explicarla, de lo precario de los primeros logros. Impuesta por el público contra la crítica, e impuesta en formas extranjerizas mal adaptadas, determinará reacciones de aquélla que le harán imposible desde un comienzo beneficiarse plenamente de la plena realidad española. Y hasta que Galdós lo comprenda y asimile su obra, esa absurda crítica, que tantas veces opuso a la novela el nombre de Cervantes, hará que éste sea una rémora en los progresos del género, nunca un estímulo ${ }^{32}$.

José F. Mon'tesinos

University of California,

Berkeley.

${ }^{31}$ La novela en España, en Obras completas, vol. Il, pág. 167.

${ }^{32} \mathrm{El}$ escrito que antecede es, apenas retocada, una comunicación al congreso de la Modern Language Association reunido en Detroit en diciembre de 1951. Me decido a publicarla porque, sin muchos más datos sobre el tema y necesitado de ellos, aspiro a conseguir la cooperación de cuantos por estos problemas se interesen. El amistoso interés con que Amado Alonso seguia estos trabajos míos sobre la historia y los problemas de la novela me impulsa a ofrecérsela en un conmovido homenaje póstumo. 